\title{
Comunicação
}

\section{Efeito da aplicação foliar de silicato de potássio e de fungicida na severidade da ferrugem da folha e da mancha amarela do trigo}

\author{
João Américo Wordell Filho ${ }^{1}$, Henrique da Silva Silveira Duarte ${ }^{2}$, Fabrício de Ávila Rodrigues ${ }^{3}$
}

\begin{abstract}
RESUMO
A ocorrência de doenças, como a ferrugem da folha (Puccinia triticina) e a mancha amarela (Drechslera triticirepentis), pode reduzir a produtividade do trigo. O objetivo deste trabalho foi avaliar o efeito da aplicação foliar de silicato de potássio (SP) e de fungicidas, no controle da ferrugem da folha e da mancha amarela, nos cultivares de trigo Safira e Quartzo. Utilizou-se o delineamento experimental em blocos casualizados, no esquema de parcelas subdivididas e com quatro repetições. Os cultivares foram alocados nas parcelas e, nas subparcelas, os tratamentos: T1 testemunha, T2 - fungicida (azoxistrobina $60 \mathrm{~g}$ i.a./ha + ciproconazol $24 \mathrm{~g}$ i.a./ha) foram aplicados nos estádios 45 (final da elongação) e 58 (espigamento); T3 - SP (40 g/L), aplicado nos estádios 45 e 58 ; T4 - SP (40 g/L), aplicado no estádio 45 , e fungicida aplicado no estádio 58 ; T5 - hidróxido de potássio $(6,5 \mathrm{~g} / \mathrm{L})$ foi aplicado nos estádios 45 e 58 . O volume de calda utilizado para as pulverizações foi de $250 \mathrm{~L} / \mathrm{ha}$. As severidades da ferrugem da folha e da mancha amarela foram avaliadas, a partir dos sete dias, após a primeira pulverização de SP e de fungicida, e, depois, a cada semana, totalizando cinco avaliações. Os dados foram utilizados para calcular a área abaixo da curva do progresso da ferrugem da folha (AACPFF) e a área abaixo da curva do progresso da mancha amarela (AACPMA). O SP, nas doses e número de aplicações avaliadas, não foi eficiente na redução da AACPMA e da AACPFF, nos dois cultivares.
\end{abstract}

Palavras-chave: Drechslera tritici-repentis, Puccinia triticina, nutrição mineral.

\section{ABSTRACT \\ Effect of foliar application of potassium silicate and fungicide on the severity of leaf rust and yellow leaf spot in wheat}

The occurrence of diseases such as leaf rust (Puccinia triticina) and yellow spot (Drechslera tritici-repentis) can decrease wheat yield. This study aimed to evaluate the effect of foliar application of potassium silicate (PS) and fungicide on the control of leaf rust and yellow spot in the cultivars Safira and Quartzo. The experiment was carried out in a randomized complete block split-split plot design with four replications. The cultivars were randomly assigned to the main plot, and in the subplots, the treatments $\mathrm{T} 1$ - control, $\mathrm{T} 2$ - fungicide (azoxystrobin $60 \mathrm{~g}$ a.i/ha + ciproconazole $+24 \mathrm{~g}$ a.i/ha) sprayed at the growth stages 45 (booting) and 58 (heading), T3 - PS (40 g/L) sprayed at growth stages 45 and 58, T4 - PS (40 g/L) and fungicide sprayed, respectively, at growth stages 45 and 58 and T5 - potassium hydroxide $(6.5 \mathrm{~g} / \mathrm{L})$ sprayed in the growth stages of 45 and 58 . The volume used in the sprays was $250 \mathrm{~L} / \mathrm{ha}$. The evaluation of leaf rust and yellow spot severity started at 7 days after the first spraying and then every week, in a total of five assessments. Data of disease severity were used to calculate the area under leaf rust progress curve (AULRPC) and the area under yellow spot progress curve (AUYSPC). The PS, at the rate and the number of sprayings, was not efficient to decrease both AUYSPC and AULRPC in the two cultivars.

Key words: Drechslera tritici-repentis, Puccinia triticina, mineral nutrition.

Recebido para publicação em 23/01/2013 e aprovado em 03/05/2013.

${ }^{1}$ Engenheiro-Agrônomo, Doutor. Empresa de Pesquisa Agropecuária e Extensão Rural de Santa Catarina (Epagri/Cepaf), Avenida Servidão Ferdinando Tusset, s/n, Bairro São Cristovão, Caixa Postal 791, 89801-970, Chapecó, Santa Catarina, Brasil. wordell@epagri.sc.gov.br (autor para correspondência).

${ }^{2}$ Engenheiro-Agrônomo, Doutor. Departamento de Fitotecnia e Fitossanitarismo, Universidade Federal do Paraná, Rua dos Funcionários, 1540, Juvevê, 80035-050, Curitiba, Paraná, Brasil. henriqueduarte49@gmail.com

${ }^{3}$ Engenheiro-Agrônomo, Doutor. Departamento de Fitopatologia, Universidade Federal de Viçosa, Campus Viçosa, Avenida Peter Henry Rolfs s/n, 36570-000, Viçosa, Minas Gerais, Brasil. fabricio@ufv.br

Rev. Ceres, Viçosa, v. 60, n.5, p. 726-730, set/out, 2013 


\section{INTRODUÇÃO}

O trigo (Triticum aestivum L.) é uma das culturas mais importantes na região sul do Brasil. A produção de trigo é limitada por vários fatores; dentre estes, as doenças têm ocupado lugar de destaque. A ferrugem da folha e as manchas foliares, principalmente a mancha amarela, são as doenças que se têm destacado na cultura do trigo no Brasil, por causarem enormes danos à cultura (Reis \& Casa, 2007). A ferrugem da folha é causada pelo fungo Puccinia triticina Erikss e os sintomas ocorrem, principalmente, no período de perfilhamento, podendo-se prolongar até à maturação dos grãos (Reis \& Casa, 2005). A mancha amarela, causada por Dreschlera tritici-repentis (Died.) Shoemaker, é favorecida por temperaturas entre $18^{\circ} \mathrm{C}$ e $28^{\circ} \mathrm{C}$ e causa maiores danos em sistema de semeadura direta, sob monocultura (Reis \& Casa, 2007).

O controle da ferrugem da folha e da mancha amarela é baseado, principalmente, na aplicação de fungicidas (Reis \& Casa, 2007). Com isso, onera o custo de produção, além da possibilidade da ocorrência da intoxicação dos aplicadores, contaminação do ambiente pela deriva, lixiviação dos excessos de produtos pulverizados, resíduos de fungicidas nos grãos e seleção de isolados do patógeno resistentes aos fungicidas, principalmente aqueles com mecanismo de ação mais específico (Duarte et al., 2012). Todos esses fatores são motivos de preocupação e têm levado a uma procura de estratégias de manejo de doenças, com produtos alternativos eficientes e economicamente viáveis. Dentre estas, destaca-se a aplicação de nutrientes no controle de doenças de plantas.

O silício ( $\mathrm{Si}$ ) tem-se destacado no controle de doenças de plantas (Datnoff et al., 2007). O Si aumenta a resistência de várias espécies vegetais, na sua maioria monocotiledônea, às pragas e às doenças (Marschener, 1995; Rodrigues et al., 2004). O Si também atua reduzindo o estresse das plantas às altas temperaturas, ao déficit hídrico e à toxidez por ferro e manganês (Datnoff et al., 2007). O mecanismo de resistência, potencializado pelo $\mathrm{Si}$, nas plantas, ainda não está totalmente esclarecido. A hipótese da formação de uma barreira física, abaixo da cutícula, após a polimerização do ácido monossilícico, explica, parcialmente, o aumento da resistência do arroz à brusone (Kim et al., 2002). O acúmulo de compostos fenólicos associados com as estruturas de alguns patógenos, o aumento da produção de fitoalexinas, a transcrição de alguns genes, associados com a resistência à brusone, e o aumento na atividade de enzimas de defesa (Datnoff et al., 2007) reforçam a hipótese de que o Si potencializa mecanismos bioquímicos de defesa das plantas, não atuando, exclusivamente, apenas de forma passiva na resistência.
Vários trabalhos têm mostrado o efeito da aplicação foliar de silicato de potássio (SP) na redução da severidade de doenças de plantas, em diversas culturas. Em soja, foi verificada redução da severidade da ferrugem-asiática, com a pulverização de SP por via foliar (Rodrigues et al., 2010). Em pepino, melão e abóbora, a pulverização foliar de SP, nas concentrações de até 17 mM (1000 ppm de $\mathrm{Si}$ ), foi efetiva em reduzir a severidade do míldio pulverulento (Menzies et al., 1992). Rodrigues et al. (2010) verificaram redução da severidade da mancha angular do feijoeiro, com a aplicação foliar de SP.

Trabalhos evidenciando o efeito do Si na redução dos sintomas da ferrugem da folha e da mancha amarela, ou na potencialização de mecanismos de defesa das plantas contra estas doenças, são inexistentes. O objetivo deste trabalho foi estudar o efeito da aplicação foliar de SP e de fungicidas, na ferrugem da folha e na mancha amarela em trigo.

\section{MATERIAL E MÉTODOS}

Um experimento foi conduzido, no campo experimental da Epagri/Cepaf, Chapecó, SC, no ano de 2009, em área cultivada em monocultura e pelo sistema de semeadura direta. As sementes foram tratadas com o fungicida iprodiona e com o inseticida tiametoxan (50 e 39,37 g i.a / $100 \mathrm{~kg}$ de sementes), respectivamente, para eliminar fontes de inóculo dos patógenos causadores de manchas foliares e para prevenir a ocorrência da virose do nanismo amarelo da cevada, respectivamente. Foram utilizados os cultivares de trigo de ciclo médio Safira e Quartzo. A semeadura foi realizada no dia 15/06/2009, na profundidade de 0,05 m, adotando-se o espaçamento de 0,20 m entre linhas. As subparcelas tiveram 1,00 $\mathrm{m}$ de largura $\times 5 \mathrm{~m}$ de comprimento, sendo utilizadas 330 sementes $/ \mathrm{m}^{2}$. Foi deixado um espaço de $10 \mathrm{~m}$ entre blocos e de $5 \mathrm{~m}$ entre parcelas, mantidos livres de qualquer cultura e de plantas daninhas. Para isolar o experimento, foi semeada uma faixa de $1 \mathrm{~m}$ de largura com centeio, distante $1 \mathrm{~m}$ das parcelas laterais do experimento.

Durante a semeadura, foi utilizada adubação de 250 $\mathrm{kg} /$ ha da fórmula 5-25-25. Aos 21 dias após emergência das plântulas, foi realizada a adubação de cobertura, aplicando-se $80 \mathrm{~kg}$ de N/ha. Aos 15 dias antes da semeadura, foi feito o controle de plantas daninhas, por meio da dessecação da cobertura vegetal do solo, utilizando-se o ingrediente ativo glifosato (1440 i.a/ha). O controle de pulgões foi realizado pela pulverização do ingrediente ativo [lambda-cialotrina + tiametoxam (5,3 i.a/ha + 7,05 i.a/ha)].

$\mathrm{O}$ experimento foi instalado em esquema de parcelas subdivididas, no delineamento de blocos casualizados, com quatro repetições. Na parcela principal, foram alocadas os dois cultivares de trigo. Nas subparcelas, foram avalia- 
dos os seguintes tratamentos: T1 - testemunha; T2 fungicida aplicado nos estádios 45 (final da elongação) e 58 (espigamento); T3 - SP aplicado nos estádios 45 e 58; T4 - SP aplicado no estádio 45 e fungicida aplicado no estádio 58 e T5 - hidróxido de potássio $(\mathrm{KOH})$, aplicado nos estádios 45 e 58. O fungicida utilizado em T2 e T4 foi azoxistrobina $60 \mathrm{~g}$ i.a/ha mais ciproconazol $24 \mathrm{~g}$ i.a/ha. As soluções de SP (Fertisil ${ }^{\circledR}$, PQ Sílicas Ltda, São Paulo; $13 \%$ $\mathrm{K}_{2} \mathrm{O}, 26,59 \% \mathrm{SiO}_{2}$ ) e de $\mathrm{KOH}$ (P.A) foram pulverizadas nas doses de 40 e 6,5 g/L, respectivamente, ajustando-se o $\mathrm{pH}$ para 5,5 com $\mathrm{HCl} 1 \mathrm{M}$. O tratamento com $\mathrm{KOH}$ foi utilizado para equilibrar a quantidade de potássio $(\mathrm{K})$ com a quantidade desse elemento presente na dose de $40 \mathrm{~g} / \mathrm{L}$ de SP. As pulverizações foram realizadas com pulverizador manual pressurizado com $\mathrm{CO}_{2}$, equipado com bicos leques XR 11002, aplicando-se 250 L/ha. Epidemias da ferrugem da folha e da mancha amarela ocorreram na área experimental por inoculação natural.

As avaliações da severidade da ferrugem da folha e da mancha amarela foram iniciadas sete dias após a primeira pulverização, realizando-se uma avaliação semanal, durante cinco semanas consecutivas, correspondendo aos estádios 50, 56, 68, 76 e, aos 87 dias após semeadura, de acordo com a escala de Zadoks et al. (1974), em dez plantas, ao acaso, por subparcela. A severidade da mancha amarela e a da ferrugem da folha foram avaliadas, respectivamente, com as escalas diagramáticas de Peterson et al. (1948) e de James (1971). Os valores de severidade foram utilizados para calcular a área abaixo da curva do progresso da ferrugem da folha (AACPFF) e da mancha amarela (AACPMA), conforme proposto por Shaner \& Finney (1977).

No final do experimento, foram coletadas todas as folhas de 20 plantas por subparcela, aproximadamente, aos 20 dias após a última pulverização. Posteriormente, as folhas foram lavadas com água deionizada, secadas em estufa, a $70^{\circ} \mathrm{C}$, e moídas em moinho tipo Wiley. A concentração foliar de Si foi determinada por análise colorimétrica (Korndörfer et al. 2004).

$\mathrm{O}$ rendimento de grãos foi determinado, colhendo-se as plantas das subparcelas $\left(5 \mathrm{~m}^{2}\right)$, com uma colhedora Wintersteiger. Após a colheita, os grãos passaram por secagem, ajustando-se o teor de umidade para $13 \%$. O peso de 1000 sementes (PMS) foi determinado com balança eletrônica de precisão de três casas decimais.

Os dados da AACPFF, da AACPMA, do rendimento de grãos e do PMS foram submetidos à análise de variância e, as médias dos tratamentos, comparadas pelo teste de Tukey, a $5 \%$ de probabilidade.

\section{RESULTADOS E DISCUSSÃO}

Houve interação significativa entre os fatores cultivares de trigo e tratamentos, para a variável AACPFF. Os tratamentos T3, T1 e T5 diferiram entre os cultivares Safira e Quartzo, ao contrário de T2 e T4, que não diferiram (Tabela 1). Os tratamentos utilizados para os dois cultivares diferiram quanto à $\mathrm{AACPFF}$, sendo esta menor nas plantas dos tratamentos $\mathrm{T} 2$ e T4, nos quais foram utilizados fungicidas. Os tratamentos T3 e T5 não apresentaram efeito no controle da ferrugem da folha, demonstrando, assim, que a aplicação foliar de $\mathrm{SP}$ e de $\mathrm{KOH}$, nas doses e no número de aplicações utilizados, não foram eficientes na redução da severidade dessa doença nos cultivares avaliados (Tabela 1). Resultado similar ocorreu em experimentos realizados com batateira e tomate industrial, sob condições favoráveis para ocorrência da requeima, em que a aplicação foliar de SP não controlou a doença (Duarte et al., 2007, Duarte et al., 2008). Em cafeeiro, a aplicação foliar de SP também não foi eficiente no controle da ferrugem, mesmo em curto intervalo de aplicação (15 dias) (Neto et al., 2007). Esses resultados diferem dos obtidos por Datnoff et al. (2007), Resende et al. (2009) e Domiciano et al. (2010), os quais reportaram o potencial do Si, fornecido por via do solo ou por solução nutritiva, em reduzir a severidade de algumas doenças economicamente importantes, em culturas como o arroz, cevada, milho, sorgo e trigo. Esse resultado positivo deve-se, principalmente, ao fato de as monocotiledôneas acumularem mais Si na parte aérea e por ter sido o Si fornecido por solução nutritiva, ou aplicado no solo, em comparação com os da aplicação foliar. Neste trabalho, a aplicação foliar de silicato de potássio não proporcionou aumento na concentração de $\mathrm{Si}$ (Tabela 1) e, consequentemente, não afetou negativamente o progresso das doenças estudadas.

Não houve interação significativa entre os fatores cultivares de trigo e tratamentos, para a variável AACPMA. O cultivar Safira (AACPMA = 257,13) foi mais susceptível à mancha amarela do que o cultivar Quartzo (AACPMA = $187,15)$, independentemente do tratamento utilizado. $\mathrm{O}$ tratamento T1 (testemunha) diferiu dos demais tratamentos. Os tratamentos T3, T4 e T5 não diferiram entre si. As plantas dos tratamentos T2 e T4 apresentaram os menores graus de severidade, demonstrando a eficiência do fungicida (azoxistrobina + ciproconazol) no controle dessa doença. Resultados similares foram encontrados por Kuhnem Junior et al., (2009), que verificaram que o fungicida (azoxistrobina + ciproconazol) é eficiente no controle de doenças foliares do trigo.

Não houve efeito significativo de tratamentos, de cultivares e da interação entre os fatores para a concentração foliar de Si. Rodrigues et al. (2001) encontraram valores variando de 1 a $1,5 \mathrm{dag} / \mathrm{kg}$ de $\mathrm{Si}$, em folhas de trigo de plantas supridas com esse elemento pelo solo. Neste estudo, a concentração foliar de Si variou de 1,1 a 1,2 dag/ $\mathrm{kg}$, assemelhando-se aos valores encontrados por Rodrigues et al. (2001). A concentração foliar de Si de até 
2 dag/kg está associada com a capacidade fisiológica inata das plantas de trigo de absorver esse elemento da solução nutritiva (Rafi \& Epstein, 1999), ao contrário das plantas de arroz, que chegam apresentar até $10 \mathrm{dag} / \mathrm{kg}$ de $\mathrm{Si}$ nas folhas (Dallagnol et al., 2009). Assim, fica demonstrado que o trigo é menos eficiente do que o arroz, no acúmulo do Si na parte aérea, como foi demonstrado por Rodrigues et al. (2001).

Houve interação significativa entre os fatores (cultivares de trigo $\times$ tratamentos) para o rendimento. $\mathrm{O}$ rendimento de grãos diferiu entre tratamentos, para o cultivar Safira. As plantas que receberam os tratamentos T2 (3456 $\mathrm{kg} / \mathrm{ha}$ ) e T4 (3470 kg/ha) apresentaram os maiores rendimentos. Esse resultado é atribuído ao efeito do fungicida no controle dessas doenças. Não houve diferença no rendimento de grãos para o cultivar Quartzo. Os valores da AACPFF e AACPMA para o cultivar Quartzo foram menores quando comparados com os do cultivar Safira, e a severidade da mancha amarela, nas plantas de todos os tratamentos, não foi suficiente para causar perda significativa no rendimento de grãos.

Houve interação significativa entre os fatores (cultivares $\times$ tratamentos), para a variável PMS. O PMS diferiu entre os tratamentos para os dois cultivares. Os tratamentos T2 $(25,75 \mathrm{~g})$ e T4 $(25,25 \mathrm{~g})$ apresentaram maior PMS, para o cultivar Safira. Para o cultivar Quartzo, os maiores valores de PMS ocorreram para os tratamentos T3, T2 e T4. O PMS é uma das variáveis utilizadas para avaliar a qualidade industrial do trigo, utilizado na produção de farinha para panificação. O peso de grãos tem como objetivo estimar sua qualidade e o seu comportamento durante a moagem (Germani, 2008).

\section{CONCLUSÕES}

A aplicação foliar de SP não foi eficiente na redução da severidade da ferrugem da folha e da mancha amarela, em comparação com a aplicação de fungicida.

\section{REFERÊNCIAS}

Dallagnol LJ, Rodrigues FA, Mielli MVB, MA JF \& Datnoff LE (2009) Defective active silicon uptake affects some components of rice resistance to brown spot. Phytopathology, 99:116-121.

Datnoff LE, Rodrigues FA \& Seebold KW (2007) Silicon and Plant Nutrition. In: Datnoff LE, Elmer WH \& Huber DM (Eds.) Mineral Nutrition and Plant Disease. Saint Paul MN, APS Press. p. 233-246.

Domiciano GP, Rodrigues FA, Vale FXR, Xavier Filho MS, Moreira WR, Andrade CCL \& Pereira SC (2010) Wheat resistance to spot blotch pontentiated by silicon. Journal of Phythopathology, 158:334-343.

Duarte HSS, Zambolim L, Mizubuti ESG, Padua JG, Ribeiro Junior JI, Carmo EL \& Nogueira Junior AF (2012) The field resistance of potato cultivars to foliar late blight and its relationship with foliage maturity type and skin type in Brazil. Australasian Plant Pathology, 41:139-155. 
Duarte HSS, Zambolim L, Rodrigues FA \& Rios JA (2008) Efeito do silicato de potássio isoladamente ou em mistura com fungicida no controle da requeima da batateira. Summa Phytopathologica, $34: 68-70$

Duarte HSS, Zambolim, L \& Rodrigues FA (2007) Controle da requeima em tomateiro industrial com aplicações de fungicidas e silicato de potássio. Fitopatologia Brasileira, 32:257-260.

Germani R (2008) Características dos grãos e farinhas de trigo e avaliações de suas qualidades. Embrapa Agroindústria de Alimentos, Rio de Janeiro. 56p.

James WC (1971) An illustraded series of assessment keys for plant disease, their preparation and usage. Canadian Plant Disease Survey, 65:389-65.

Kim SG, Kim KW, Park EW \& Choi D (2002) Silicon-induced cell wall fortification of rice leaves: a possible cellular mechanism of enhanced host resistance to blast. Phytopathology, 92:10951103.

Korndörfer GH, Pereira HS \& Nola A (2004) Análise de silício: solo, planta e fertilizante. Grupo de Pesquisa em Silício. Uberlândia, ICIAG-Universidade Federal de Uberlândia. 34p. (Boletim Técnico 1)

Kuhnem Junior PR, Casa RT, Rizzi FP, Moreira EN \& Bogo A (2009) Desempenho de fungicidas no controle de doenças foliares em trigo. Ciências Agroveterinárias, 8:35-42.

Marschener H (1995) Mineral nutricion of higher plants. London, Academic. 899p.

Menzies J, Bowen P, Ehret DL \& Glass ADM (1992) Foliar applications of potassium silicate reduce severity of powdery mildew on cucumber, muskmelon, and zucchini squash. Journal of the American Society for Horticultural Sciense, 117:902905 .

Neto PNS, Zambolim L, Souza AF, Rodrigues FA, Fontes LFP Lopes UP \& Duarte HSS (2007) Efeito da aplicação foliar de silicato de potássio no controle da ferrugem do cafeeiro (Hemileia vastatrix Berk. Et Br.). In: Congresso paulista de fitopatologia, Jaboticabal. Anais, Summa Phytopathologica supplement. p.51.
Peterson RF, Campbell AB \& Hannah AE (1948) A diagrammatic scale for estimating rust intensity of leaves and stem of cereals. Canadian Journal Research Sect, 26:496-500.

Rafi MM \& Epstein E (1999) Silicon absorption by wheat (Triticum aestivum L). Plant and Soil, 211:223-230.

Reis EM \& Casa RT (2005) Doenças do Trigo. In: Kimati H, Amorim L, Bergamin Filho A, Camargo LEA \& Rezende JAM, (Eds.) Manual de fitopatologia: doenças das plantas cultivadas. 4.ed. São Paulo, Agronômica Ceres. p.631-638.

Reis EM \& Casa RT (2007) Doenças no Cereais de Inverno: Diagnose, Epidemiologia e Controle. 2 ed. Lages, Grapel. 174p.

Resende RR, Rodrigues FA, Soares JM \& Casela CR (2009) Influence of silicon on some components of resistance to anthracnose in susceptivel and resistance sorghum lines. European Journal of Plant Pathology, 124:533-541.

Rodrigues FA, Duarte HSS, Rezende DC, Filho JAW, Korndörfer G H \& Zambolim L (2010) Foliar spray of potassium silicate on the control of angular leaf spot on beans. Journal of Plant Nutrition, 33:2082-2093

Rodrigues FA, Korndörfer GH, Corrêa GF, Buki GB, Silva AO \& Datnoff LE (2001) Response of six gramineae species to application of calcium metasilicate. In: Datnoff LE, Snyder GH \& Korndörfer GH (Eds.) Silicon in Agriculture. Amsterdam, Elsevier Science BV Studies in Plant Science. 424p.

Rodrigues FA, McNally DJ, Datnoff LE, Jones JB, Labbé C, Benhamou N, Menzies JG \& Bélanger RR (2004) Silicion enhances the accumulation of diterpenoid phytoalexins in rice: a potential mechanism for blast resistance. Phytopathology, 94:177-183

Shaner G \& Finney RE (1977) The effect of nitrogen fertilization on the expression of slow-mildewing resistance in Knox wheat. Phytopathology, 67:1051-1056.

Zadoks JC, Chang TT \& Konzak CF (1974) A decimal code for the growth stages of cereals. Weed Research, 14:415-421. 